$\mathrm{O}$ artigo parte da pesquisa em andamento sobre as manifestações da crise da adolescência como indicador dos efeitos da ciência no campo do sujeito, que tem por objeto as transformações que a ciência opera não apenas na realidade, mas também sobre a linguagem como campo em que o sujeito se constitui. Visa a situar a discursividade própria das pichações de rua referida à subversão promovida no funcionamento ordinário da linguagem e baseada na análise das incidências das operações transformadoras do discurso_sobre o sujeito que estão na origem de nosso funcionamento social contemporâneo ordenado pela ciência.

Graffiti; ciência; sujeito; contemporaneidade; lalangue

STATEMENTS FROM THE ONES WHO HAVE NOTHING TO SAY: CONTEMPORARY ADOLESCENTS AND THEIR GRAFFITI

The work is part of the research in progress about the adolescence crisis as an index of the effects of science on the field of the subject which starts from the fact that science not only transforms the reality we live in, but also language as the field on which the subject must take place. The article then tries to demonstrate that there is discourse in the graffiti adolescents spray on the walls, a discourse that reefers to the operations science imposes on language so as to rule our contemporary social order.

Graffiti; science; contemporary social order; lalangue

\section{MANIFESTOS DE QUEM NÃO TEM O QUE DIZER: ADOLESCENTES CONTEMPORÂNEOS E OS GRAFFITI DE RUA ${ }^{1}$}

A ndar nas ruas e não vê-las é impossível. As pichações são enormes e buscam os locais mais visíveis. As prefeituras gastam fortunas tentando apagá-las. A polícia é mobilizada para combater o estrago. Em vão. Estima-se que há mais de duzentas gangues espalhando graffiti só no Rio de Janeiro. Multas e prisões, em lugar algum, nada consegue contê-las. Mesmo soluções como a montagem de paredes especiais ("reservado para spray" informava a placa ao lado da lanchonete por onde passei certa vez) não têm se mostrado satisfatórias (a parede da lanchonete era pichada como todas as outras em volta).

Quem passa pelos grandes centros urbanos hoje sabe bem o que os graffiti podem deflagrar: interferência, irritação, confusão de variável intensidade. Como bem observou Baudrillard (1976), nas vezes

Psicanalista, membro do Tempo Freudiano Associação Psicanalítica. Pesquisadora docente em programa de fixação apoiado pela FAPERJ - Programa de Pós-Graduação em Teoria Psicanalítica, IP/UFRJ. 
em que uma placa de trânsito, um muro, uma escola, um camburão aparecem pichados, invadidos por aquelas escrituras estúpidas, indecifráveis - é a sinalética urbana que se embaralha, a ordem dos signos que se desfaz.

É interessante que sejam bandos adolescentes que se aventurem a fazê-las. Em plena era da comunicação pela Internet, em que qualquer um pode ousar não importa o quê, desde que transformado em matéria de blogs e flogs e "comunidades", com acesso ao mundo da cadeira de casa e em tempo real, o que faz com que jovens usuários da www troquem o instantâneo pelo esforço de planejamento, execução e risco envolvido em pichar muros?

Diz-se que a onda partiu dos jovens habitantes dos guetos (Castleman, 1982), justamente o território daqueles a quem não se consulta (Castro, 2001), veiculando o que o libelo de um grande jornal dos anos 90 chamava de "manifestos de quem não tem o que dizer" (Jornal do Brasil 20/8/88). Mas o fato é que terminou por invadir, numa espécie de fúria, inúmeras cidades grandes e pequenas de todo o mundo, cobrindo-as de grafismos rudimentares ou sofisticados, cujo conteúdo não é nem político, nem pornográfico e de nenhum modo programático: apenas palavrinhas curtas, apelidos, onomatopéias (vêm dos quadrinhos, dos filmes, de qualquer lugar) que não têm sequer originalidade e diante das quais... 'Snuhhghr', o que dizer?

Irredutíveis por sua própria pobreza (e não deixa de ter sua graça o fato de que os "redutores" de tinta nada possam contra isso), as marcas desses jovens inscrevem-se no vazio em que os elementos tradicionais do discurso (o sujeito, a frase, o verbo) não têm mais lugar.

A conseqüência imediata é que, não podendo falar nem do autor, nem do assunto, nem do estilo, parece que nada mais se pode dizer sobre esse texto. E nesta direção, se os condenamos, se reclamamos apenas da sujeira que fazem, o que anunciam como negatividade escapa como positividade - "ação que se quer" - investimento e tática do desejo. Afinal, é forçoso reconhecer que ostentar o inútil, borrar, embaralhar a ordem dos signos na cidade, ameaçar a pintura branca dos monumentos, quando "não se tem o que dizer", constitui um exercício prodigioso, se se tem em conta sua estratégia particular de subversão (do estabelecido) e de subtração (do discurso) a partir do mínimo, do passageiro.

De um modo geral, a ideologia tende a reduzir essas formações ao erro, recuperando as pichações como exibicionismo ou revolta adolescente, interpretando-os em termos de reivindicação de identidade ou de liberdade pessoais, de "ser notado", ainda que conservando o anonimato. Entretanto, essa manobra deixa escapar o fato, central, de que esses pequenos escritos não significam 
nada, não promovem nenhum enunciado. Pelo contrário, reproduzem mal os sinais escritos da língua, inventam, homenageiam as letras. Todas as noites, jovens invadem garagens de ônibus, sobem e se dependuram nos prédios e se arriscam, elaborando um $a$, sublinhando um $o$, acrescentando uma perna inusitada ao ₹... Vindos da linguagem e parecendo permanecer nela, eles executam suas garatujas, às expensas do próprio corpo.

Dito de outro modo, o grafiteiro não empenha seu esforço na matéria verbal, mas na decisão de escrever (no corpo da cidade e correndo todos os riscos). Tudo aqui é entregue à escritura, e essa delegação se realiza num trabalho com a forma - o artesanato é a condição necessária do estilo (o contínuo da escritura é questão de velocidade e essa velocidade é, em última análise, a da mão). 'JiyinKx'!, escrevem. E essa escritura não explora um saber, não veicula um sentido nem ilustra um tema. Sua força não está no conteúdo ou na mensagem, mas no gesto que a produziu.

A questão que se impõe então - e à qual a significação em termos de revolta ou reivindicação não responde verdadeiramente - é a de tentar reconhecer, no movimento de apreensão da linguagem que os graffiti realizam, não o seu dito, mas o dizer que eles veiculam.

O presente trabalho visa a situar uma discursividade própria a estes escritos, na medida em que eles testemunham, pela subversão do funcionamento ordinário da linguagem que promovem, a incidência das operações transformadoras do discurso que está na origem de nosso funcionamento social contemporâneo, ordenado pela ciência.

Um dizer, portanto - ao menos assim o propomos - referido à ordem discursiva introduzida pela ciência e pelo qual se testemunha o efeito sujeito em sua presença intempestiva nas ruas, nas escolas, nas unidades de saúde ou da justiça etc.

\section{Emergência do sujeito no real}

O costume de pichar os muros tem uma longa história, pródiga em acontecimentos inusitados, envolvendo atos que indiciam e requerem, ou implicam diretamente, um sujeito como agente (Jean, 2002). A ficarmos apenas - e inicialmente - no exemplo corriqueiro e, no entanto, gritante, relacionado aos graffiti de rua inscritos nos lugares mais improváveis, constatamos o que, em última instância, apenas o ato de um sujeito é capaz de produzir. Pois esta escritura armada, guiada por (e para) uma ilegibilidade, pro- 
duz um texto ardente, que prende e se refaz continuamente fora de qualquer significação.

Há, por outro lado, uma constante reversão (pontual, que não dura) dessa falta de significado (negatividade) em uma significação (positividade), a partir da explicitação, que eles realizam, de aspectos determinados da relação do sujeito com a linguagem na contemporaneidade.

Por exemplo, diz-se que os graffiti são vazios. Mas toda linguagem é um vazio (do ser, da coisa) e uma construção significante vem preenchê-lo. Por levarem a linguagem até sua mais áspera realização, os graffiti indiciam essa ausência de modo mais intenso. Apontando ao mesmo tempo para um modo de emergência do sujeito - louco, indomável, irascível, verdadeira "aparição" do sujeito na placa de rua - que remonta diretamente à ordem discursiva, introduzida pela operação da ciência.

É como efeito da formalização que esse vazio da linguagem aparece. Até o advento da ciência, o mundo era fechado (Koyré, 1966) e com sentido (cosmo). O real, se havia, era "pleno", habitado por deuses que vinham misturar-se aos homens, o que fazia com que as contingências aparecessem como parte de uma ordem maior que sempre prevalecia. Não havia fronteira e, nesse sentido, não havia um lugar Outro, antes que a formalização da ciência, a matematização dos caracteres em que a natureza está escrita viesse, de um golpe, instituir o real como o experimentamos, isto é, como presença do impossível a cernir na linguagem.
Com a emergência da ciência, e através dela, o sujeito é depurado do que lhe assegurava estabilidade e consistência imaginária (seu lugar social pré-fixado, a referência de suas ações a um conjunto dado de valores tidos como universais, a nitidez de ideais que governava a sua sexuação etc.) e privado de características intrínsecas que lhe permitam definir-se ou identificar-se a si mesmo. O que resulta daí é um sujeito assubstancial, cuja existência encontra-se reduzida à pontualidade de um cogito que só tem acesso à certeza de si como ato.

A noção de sujeito do inconsciente responde, justamente, à emergência na clínica desse sujeito que se constitui, doravante, como um resto pontual, heterogêneo e, no entanto, "ineliminável" da própria operação da ciência, testemunhado no registro da enunciação.

Os adolescentes, por conta da suspensão mais ou menos prolongada que os atinge como sujeitos (Melman 1997 e 2002), e por serem mais suscetíveis à transformação tecnológica são aqueles que encarnam com mais radicalidade essa condição extrema que é a do sujeito desamarrado das amarras simbólicas que poderiam sustentar seu lugar tenente, na contemporaneidade.

Essa condição se manifesta em seus impasses, seus atos e patologias. Muitas vezes, com a contundência de um rasgão, corte feito no real pela negatividade irredutível de atos tresloucados ou dos sintomas que não cessam, condenando a adolescência a configurar comumente em nossos dias uma crise não apenas do ponto de vista subjetivo, mas também no 
que toca as alternativas discursivas que temos a oferecer ao adolescente ${ }^{2}$.

As pichações realizadas por esses jovens que se encontram confrontados à tarefa de tomar lugar na vida social parecem assinalar essa posição do sujeito que busca incessantemente se apreender na linguagem como único campo no qual lhe é dado comparecer, pontual e evanescentemente, em sua articulação com o funcionamento social contemporâneo, ordenado pela ciência.

Lacan (1965) identifica explicitamente o sujeito da psicanálise ao sujeito da ciência. Mas acrescenta que a ciência foraclui o sujeito, empregando um termo jurídico que se refere à impossibilidade de integração (ou reintegração) de um dado termo da operação, uma vez que seu ciclo se complete. Como resto da operação científica, por definição, o sujeito é o que deve desaparecer, ser excluído, expulso da identidade buscada pela ciência. Resto que, por isso motiva a reiteração da operação, a repetição e mesmo a intensificação de seu ciclo. Assim, se o sujeito representa o heterogêneo produzido pela operação da ciência, o próprio jogo combinatório da ciência tenderia a eliminá-lo. Isso não é tão simples porque é justamente quando, por sua operação, a ciência busca realizar a unidade do saber, eliminando o ponto de falha e a diferença absoluta que convoca e requer $\mathrm{O}$ sujeito, que ela produz seu resto heterogêneo na figura do retorno do sujeito no real. A ciência como operação discursiva se define pela própria impossibilidade de seu esforço de suturar o sujeito e fazê-lo desa- parecer sob o saber (Glynos, 2002; Lacan, 1968; Sampaio, 2000).

Por outro lado, é ainda Lacan quem o nota (1969-70), essa extração do sujeito de sua condição simbólica singular é uma condição necessária para que o capitalismo articule seu processo produtivo. Um processo que se caracteriza pelas técnicas de adequar as demandas aos itens produzidos pela ordem econômica e social.

O que a ciência tenta fazer, portanto, é reintroduzir o sujeito como ponto de fuga no cálculo. E, no contexto das sociedades capitalistas, reintroduzí-lo no cálculo da demanda.

Muitas vezes são os jovens que tomam em mãos a tarefa de demonstrar em ato que isto não é inteiramente realizado. Isto só é realizável até certo ponto. Exibindo nos muros o que nos faz gaguejar em nossa própria língua, se tentamos "ler", algo resiste naquelas escrituras. Algo que não se deixa recuperar como positividade, identidade; que aparece e se faz contar como negatividade, diferença, vazio, convocando o sujeito.

Se, no roldão da ciência, para testemunhar sua existência limitada à pontualidade do cogito o sujeito tem que tomar posição em relação ao saber que lhe é imposto, muitas vezes a única possibilidade de posicionamento que ele encontra é a recusa. É furtar-se ao saber, à transparência das linguagens pretensamente instrumentais, operatórias, como modo de afirmar que algo aí resiste a ser tomado no cálculo.

Os graffiti presentificam então o sujeito, não pelo que dizem, mas na sua insistência em (não) dizê-lo. Em 
dizê-lo de uma forma determinada - ilegível, irredutível, incodificável. Fabricando uma escrita que não diz, os graffiti confrontam-nos com tudo o que há de ideológico, de inconsistente em nossa relação com a linguagem. São aquelas palavras fortes, mas opacas, que não permitem naturalização sob o sentido e se mostram apenas, sem remeter a significados últimos, estáveis, fechados. E porque a operação do sentido ali não se completa, é a questão da linguagem que se desvela. Ei-nos diante de uma escritura cuja função não é mais comunicar ou exprimir apenas, mas que impõe, e entrega como espetáculo, a irrupção do sujeito na linguagem.

É a esta emergência do sujeito no real, a partir das brechas da linguagem, que concerne a existência dos graffiti. A cada vez que nos confundem, o que eles retomam é essa fratura dos processos identificatórios, através dos quais os sujeitos sempre buscaram posicionar-se na existência e que a ciência torna problemáticos. O real do sujeito como corte na suposição de identidade é o que eles agenciam. Nesse nível, o sujeito aparece igualado à pulsão, uma vez que ele se manifesta apenas nos limites da representação e extrapola, pela repetição insensata de certos móveis, certas marcas que o assinalam no plano do discurso social, a possibilidade de um acordo total entre o sujeito e a ordem proposta pelos ideais sociais baseados no princípio do prazer (Fernandes, 2005).

Trata-se, portanto, de um sujeito de certa forma "assubjetivo" - não é à toa que as palavrinhas são tão estúpidas - a medida em que dele, só 
temos a atualidade de sua manifestação, impossível de apreender, nos limites de uma consciência de si, por seu caráter de corte, irrupção, descontinuidade.

Os graffiti exibem então os vestígios do sujeito na forma das garatujas, mas não para simplesmente advogar para este sujeito uma singularidade inefável. Fazer isso seria reconduzi-lo ao obscurantismo mais utópico. Ao reduzir a presença do sujeito a um conjunto de letras e sinais, as pichações mimetizam, falseiam, trapaceiam o saber da ciência - esse saber que é feito de letras que se conjugam para além da consciência, do sentido e do significado e cuja incidência é real.

Os graffiti aparecem então como uma formação discursiva que encena e destaca esse sujeito depurado, descolado da identidade. Digamos, parafraseando Lacan em L'étourdit (1978), que o muros pichados recolhem o efeito sujeito como resposta no real.

Uma ruptura de nossa

relação subjetiva à linguagem

Vários autores já assinalaram, na emergência da ciência, uma alteração radical de nossa relação subjetiva à linguagem. Para Koyré (1961-6) e Hottois (1992) a matematização e formalização que estão implicadas na operação da ciência não consistem apenas, como se poderia pensar erroneamente, na substituição de uma linguagem antiga (linguagem da na- 
tureza ou aristotélica) por outra (a linguagem dos caracteres matemáticos de Galileu), mas, antes, numa transformação muito mais ampla que atinge o próprio funcionamento da linguagem como campo em que o sujeito deve advir.

Com o curso da ciência na contemporaneidade, podemos inicialmente atribuir esses efeitos ao próprio imperativo de certeza que vem com a matemática. O projeto científico de erradicação do conflito pela via da demonstração e, notadamente, a numerização que isso implica tendem a provocar uma abolição da questão sobre o sentido e, conseqüentemente, um apagamento do lugar do sujeito (Melman, 2002). Com isso, vemos cada vez mais a autoridade passar dos lugares e funções aos fatos, definidos e validados exclusivamente em função de sua coerência interna. O resultado é que os efeitos desse imperativo de certeza se fazem sentir num escopo muito maior do que o do "debate científico" e pesam diretamente, por exemplo, na eficácia da palavra como meio de ordenação do laço social (Lebrun, 1997).

Porém, mais importante ainda é o fato de que a substituição do sistema significante da linguagem ordinária (que é sustentado na diferença) pela axiomática matemática (composta pelo movimento automático de proposições que se sucedem, a partir da aplicação de regras aparentemente "sem comando") implica uma restrição (ou anulação) da ação daqueles operadores ${ }^{3}$ que fazem com que a linguagem incida sobre ela mesma e se transforme sob o efeito dessa operação, produzindo toda a gama de efeitos que lhe são próprios, incluído aí o efeito-sujeito (Fernandes, 2005). Sim, porque dado que esses operadores realizam justamente a função de demarcação do sujeito (lugar tenente) na linguagem, pode-se aquilatar o efeito de tal encaminhamento para a operação de representação do sujeito na linguagem.

Um traço bastante distintivo dessa relação com o saber que toma corpo com o curso da ciência na contemporaneidade - e que incide especialmente sobre os adolescentes - é a supervalorização da eficácia. Melman (2001) observa que, como o saber científico é de ordem operatória, o que ele promete é predição e domínio do real, a partir de um saber-fazer notavelmente eficaz, o qual não se teria senão que gerir o mais proveitosamente possível. Os adolescentes, como todos nós, depois do advento da ciência, têm a impressão de que o saber que conta, assim, é o saber imediatamente verificável em suas aplicações práticas. E mesmo, as características de um saber teórico, epistêmico um saber passível de equivocação (ao menos em tese) e que, portanto, não poderia prescindir nem da referência ao Outro (à tradição, por exemplo) e nem da apropriação e do ato do sujeito - tendem hoje a constituir um obstáculo para o sujeito vir a localizar-se, na medida em que o que é solicitado é que ele se baste nesse saber-fazer que o conduz e o engaja tão notavelmente.

Esse implícito operatório da ciência vai mesmo produzir mutações nas línguas que, por um lado se enriquecem de novas palavras em sua dimen- 
são descritiva e informativa e, por outro, se empobrecem no que toca aos representantes que elas podem oferecer para o sujeito. A escrita-internet, por exemplo, instrumento da vastíssima comunicação entre os jovens por mídia eletrônica, cria e impõe novas modalidades de apreensão da linguagem e dos textos; segue a direção da logicização e binarização da linguagem (Freitas, 2001), com inúmeras conseqüências que é preciso ressaltar.

Escrita instrumental, gráfica e volátil, ligada ao uso do teclado e do mouse, que se logiciza e compacta cada vez mais, deixando de lado o esforço do manuscrito, inventando palavras e alterando as grafias, trata-se decerto de uma nova invenção da escrita (tão radical quanto isto). Porém Lebrun (1997) adverte que essa língua logicizada tinha sido concebida por Orwell como a novlingua em 1984. Uma língua cujas nuances pudessem gradualmente ser suprimidas no intuito de levar a língua até o extremo de seu uso exclusivamente operatório. Bom e mau, por exemplo, poderiam ser substituídos por bom e não bom (inbom). E, excelente, esplêndido, melhor por plusbom, duploplusbom etc. Uma língua composta de palavras desembaraçadas de toda ambigüidade, em que expressões não ortodoxas são quase impossíveis. Não há metáfora no sentido de produção de um sentido novo. Em Orwell a novlíngua é uma língua artificial cujo objetivo é tornar impossível qualquer outro modo de pensar. Uma língua que só encolhe - quanto menos escolha de palavras, menos tentações de refletir - seu progresso é encolher.

Com a ciência, ao contrário, a coisa é bem mais sutil e real. Enquanto a ciência subverte a relação subjetiva à linguagem por meio de uma virtual redução da linguagem à lógica, ela excerta da linguagem e seu funcionamento tudo o que não obedece às leis algébricas de grupo e à prevalência da lógica da - ou cujas operações reconduzem sempre à - identidade.

Os graffiti, que são filhos dessa formalização que a ciência impôs à linguagem, libertando-a da injunção de significar, contrapõem-se entretanto, continuamente a esta manobra que visa a reduzir a linguagem à identidade. Tudo neles provém do ambíguo. São a própria confusão da escrita formal. Nada há neles que não enseje o equívoco - até sua matéria: 'Snurghbhh'é mesmo uma palavra? É mesmo feita de letras? É e não é e aí é que está. Nas pichações, a escritura é um espaço, uma distribuição, uma geometria; corre pela superfície da comunicação (a letra, a palavra, o significante), mas sem realizá-la. A formalização aqui trabalha para o mal-entendido; contra a transmissão.

Os graffiti perturbam esse paradigma introduzido pela ciência na linguagem. Não se curvando ao binarismo ordenado pelas leis algébricas de grupo, insistem no que é mesmo o avesso dessas leis, 
a heterogeneidade, a dissimetria e a irreversibilidade como operações na ordem do discurso. Subvertendo as leis algébricas de grupo, sustentam em sua prática o que há de mais próprio à linguagem: referir a subjetividade à ação operatória da diferença, e não a anulação da mesma.

\section{Falta na língua}

Dizíamos, no início, que as pichações trapaceiam com a linguagem, mantendo, em plena era dos "bytes", o "impuro" do corpo JiyinKx!" é gesto.

É também nesse sentido que Lacan cria o termo lalangue para caracterizar uma alíngua (segundo a tradução de M. D. Magno), evocando seu sistema fonético. Dizer alíngua numa só palavra é justamente designar a língua com o som, a língua com a qual se goza. Língua equívoca (homofonia, mal-entendido) e sem mestria (ou antes da mestria) que a análise depreende dos ditos e cujos efeitos ela recolhe.

Lalangue é, portanto, o termo forjado por Lacan (1972-3) para designar a língua, destacando o que há de imperfeição e falta na língua, e contrapô-la à langue dos lingüistas. Tendo como premissa a divisão do sujeito, Lacan enfatiza a parcialidade e a falha do discurso. Dizer sujeito dividido não é senão dizê-lo sujeito de um saber que ele não sabe e que aparece na fala, especialmente quando falha (são os atos falhos, o chiste, o esquecimento) ocupando o lugar da verdade, isto é, daquilo que fala afinal (o inconsciente sujeito). Lalangue assim, não é a langue. O conceito (dicotômico) langue/parole de origem saussureana faz distinção entre o sistema lingüístico e suas manifestações efetivas. A langue é o sistema de uma língua, a língua como conjunto de formas, instituição ("Tesouro depositado pela prática da fala em todos os indivíduos pertencentes à mesma comunidade." Saussure, 1916, p. 21) enquanto a parole é a fala real, realização em instâncias reais (atos de fala) daquilo que a língua torna possível. Dessa perspectiva, a língua é sistema, vale dizer, um todo ordenado. A langue, plano do signo (que é a amarração, tênue que seja, do significante ao significado) é também o plano do sentido. E o sentido (atribuição de sentido e verificação de uma ordem antecipada) é o que caracteriza a consciência - ordenação, unificação, totalização do mundo.

Lalangue, ao contrário, é a língua na medida em que a própria língua é imperfeita. Enquanto ela permite (por suas unidades e as regras de combinação entre elas) que se fale sem dizer nada; dizer o que não se sabe, e não dizer senão imperfeitamente $o$ que se sabe.

Não há nenhum procedimento que pontue, no interior da língua, a verdade ou o falso. Mas o a priori do uso e do funcionamento da linguagem é que isso não se veja. Fingir saber, fingir o saber do verdadeiro e do falso é a impostura que sustenta o discurso e põe o sujeito a aspirar uma apreensão das coisas pela linguagem.

Os graffiti, por sua mera presença, desfazem esse engodo. O que eles 
mostram é que o real do língua não é calculável. Ele é percorrido de falhas, brechas (onde está o sujeito) e que aparecem no nível mesmo da formalização. Não há mestria, domínio possível da língua ou, como diz Lacan, "não há metalinguagem" (1972-3, p. 160). O que há é alingua: sua própria aparência posta no lugar de agente, no discurso dos pichos.

Neste sentido os graffiti desencadeiam o que a ciência domestica. Recolhem o impuro da língua, o que a lingüística refuga - a corrupção, a evanescência, a distorção da mensagem; a língua viva. $\mathrm{E}$ a língua viva é feita de mal-entendido: cada enunciação demonstra como a mesma cadeia significante é flexível e que não há momento de linguagem que o equívoco e a ambigüidade não corroam, não distorçam, não metamorfoseiem. O mal-entendido é o motor do que Lacan chamou alíngua e que faz os graffiti.

A lógica, como vimos, é uma tentativa de dominar alingua. Porém as línguas formais esbarram em que não se pode, dizendo a verdade, dizê-la toda; em que dizer a verdade, não é o mesmo que não dizer o falso. No artigo A negativa, Freud (1925) comenta que o conteúdo de uma imagem ou idéia recalcada pode abrir caminho até a consciência, sob a condição de ser negado. Um "não é minha mãe" dito de uma paciente a propósito de uma figura presente em seu sonho, leva o analista a afirmar que é justamente da mãe que se trata uma vez que a palavra está dita (e se de todo um universo de pessoas que poderiam não ser, a paciente escolhe justamente sua mãe para dizer que 
não é, é dela mesma que se deve tratar: o não que a precede sendo a marca da repressão).

O texto de Freud mostra que, quando falamos, a verdade do que dizemos pode ser outra do que o que se diz e mais: que esse outro dito em nosso próprio, constitui o dito de Outro (isto é o inconsciente) que só pode ser dito através desse dizer outro, que é a nossa fala.

Enquanto as linguagens formais produzem regras, a escritura permanece submissa a um regime estrito de sentido. A alternativa que representam é a do paradigma puro do sentido e da linguagem sem falha, sem transbordamentos; da linguagem (pretensamente) indiferente, promovido sobretudo pela ciência que promove um discurso ao mesmo tempo formal (propício a notações) e claro (almejando o unívoco).

Porém, ao contrário daquilo com que sonha a lógica, toda construção lingüística gera uma perda. Há um destino de opacidade na linguagem (abstração, separação e morte da coisa) que faz com que aquilo de que se fala seja já perdido. O próprio signo saussureano o mostra, na medida em impôs ao esquema idealista da representação (o significante em relação com o significado) uma hiato, uma diferença significante/significado que é uma barreira intransponível. Falta, portanto, algo na língua. É assim que, a cada vez, o sentido, a coisa, o sujeito, o mundo podem se inscrever nesse lugar como tantas maneiras de faltar da língua. Isto é o que a lingüística e a lógica não fizeram figurar em suas reconstruções da linguagem: a falta que sempre volta, o real que "nunca cessa de não se inscrever" (Lacan, 1972-3, p. 126).

Que os discursos se multipliquem, se produzam sem parar, vem disto: que não se pode calar o que não se pode dizer. E não paramos de tentar dizer tudo. A experiência analítica justamente quando convoca o sujeito a este "dizer tudo" não pretende apenas aumentar o escopo dos ditos do sujeito. Ao contrário, a psicanálise existe porque - este é o sentido do inconsciente - atua no discurso uma lógica que impede dizer tudo. Não se trata de impotência do sujeito, mas antes, de impossibilidade.

Lacan designa então o real como esse impossível que brota do manejo dos signos, dos signos positivos, materiais de que uma língua é feita. Nesse sentido, ele retoma (1972-3) a fórmula famosa e incessantemente repetida, "o inconsciente estruturado como uma linguagem", para dizer que o inconsciente é o que reivindica um lugar para esse impossível de dizer. O inconsciente, afirma Lacan (pp. 126-7), é o lugar de onde esse impossível (o real) pode receber sua estrutura já que ele depende da lógica do discurso e é circunscrito a partir de seus impasses (atos falhos, chistes, esquecimentos). 
Os graffiti parecem provir desse ponto irredutível no que eles são o que há de inintegrável ao discurso. A dificuldade que experimentamos na aproximação desse discurso talvez venha de que colocamos sempre a questão "o que querem dizer"4. Mas justamente os graffiti não parecem obra de "quem se sente com coisas a dizer". Enquanto procuramos o sentido sob as pichações, nos deparamos com círculos viciosos, pois elas penetram umas nas outras, proliferam ao abrigo da noite, e deixam sempre algo de fora. Há algo que não dizem, e não dizer é sua ação. O que elas dizem não pode ser dito. E sempre se repete.

Se falta na língua alguma letra para o que não se pode dizer, os graffiti vão alhures, noutra direção. Em lugar de designar esse impossível, eles o exibem. O impossível aqui sai da linguagem e ganha os muros.

Sair da linguagem só é possível porque a linguagem não é alíngua. A linguagem, mostra Lacan (1972-3), é secundária em relação à alíngua. É aquilo que o discurso (e a ciência) elabora para dar conta da alíngua. Tentativa de reconstrução da alíngua sob o conceito: "Se eu disse que a linguagem é aquilo com o que o inconsciente é estruturado, é mesmo porque a linguagem de começo, ela não existe. A linguagem é o que se tenta saber concernente à função da alíngua" (p. 189).

A questão de como a ciência tenta dominar a linguagem não é outra senão a de como o Um chega à linguagem para dividi-la (isto é linguagem/isto não é); de como este Um aí se encarna, toma "corpo de linguagem" isto é, chega a se inscrever nela como se dela fizesse parte. Esta tomada do todo sobre alíngua, é o sentido; e a linguagem é o efeito dessa dominação do significado sobre alingua. O sentido é o que em nome do Um (o que Lacan chama o "significante mestre") domina alíngua para dela extrair um conceito de linguagem; ao passo que ela, a alingua, vive da falta, se nutre da falta que ela é e se sustenta no mal-entendido, no impossível de dizer.

Lacan enfatiza ainda que o inconsciente é também uma abordagem da alíngua. Seu privilégio é que o inconsciente é um saber que escapa ao ser; ele resulta da presença da alíngua no falante articulando verdades que vão mais longe do que aquilo que ele suporta como (saber) enunciado. Diz Lacan: "A linguagem sem dúvida é feita de alíngua. É uma elucubração de saber sobre alíngua. Mas o inconsciente é um saber, um saber-fazer com a alingua. E o que se sabe fazer com alingua ultrapassa de muito o que podemos dar conta a título de linguagem" (p. 190).

O testemunho disso está nas ruas. As pichações são feitas de alíngua. As escrituras são feitas de não importa o quê de tudo o que corre na língua: letras, aspas, algarismos, notações, desenhos, gírias, expressões... Todos os recursos são ali reprocessados, reinventados a pretexto. Funcionam como emblemas, e ser emblemas os dispensa de aprofundar o sistema (a língua) de que são os significantes (aqueles que simplesmente acenam). O que os graffiti colocam é uma marca, sua letra, como cicatriz. 
'Snurghrl'- que sentido tem? Não tem sentido nenhum. É apenas letra. Mas uma vez havendo uma marca, inscrita no que é do Outro, (seja o muro, seja o inconsciente) ela começa a produzir sentido. Isto é alingua. Pura superfície. Não vende nada, não é messiânico, nem apocalíptico. Não incita à desordem, não tem mensagem. Os graffiti confiam em que o significante não significa nada. As pichações, por isso, escapam inteiramente ao paradigma representacional da linguagem. O que se vê rabiscado nos muros e paredes das cidades é um silabário que não tem mais qualquer relação com a representação; uma escritura que não tem outro conteúdo a não ser a expressão de sua forma, do gesto que lhe deu origem.

Por isso mesmo, o Outro que cada um de nós é se vê aí implicado. Ao libertar a linguagem da tutela do discurso os graffiti impõem-se, e quem os vê, desfamiliariza seu mundo, porque experimenta, por um momento que seja, desempenhar a tarefa inútil de enunciá-los, ou de enunciar seu significado (se há significante, deve haver um significado) em alguma outra metalinguagem que pudesse ordená-los - o que evidentemente é impossível, já que eles não têm qualquer relação com a hierarquia das linguagens. 'Snurgrlh, hhb' é um vazio, ou borda de um furo da linguagem. Tudo pode ali se colocar, mas como substituição impossível. Nada explica, nada preenche, porque lá só há o significante; nada substitui o significante (nada o identifica definitivamente), apenas o faz deslizar.

Vale dizer, o real, a defasagem entre o sujeito e o mundo se faz va- 
ler ali como irredutível e, ao assinalar-nos este irredutível, os graffiti nos instalam como responsáveis pela determinação. As garatujas têm, portanto, uma potência: tratam de propor ao sujeito que passa por elas seu próprio posicionamento em relação à diferença que o atravessa.

Especialmente para nossa época , que assiste entre encantada e estarrecida o avanço da ciência, outorgando-lhe o saber sobre o que nos convém e a responsabilidade de decidir por nós, é importante acolher a negatividade dos graffiti como negação (do sentido, da manipulação da linguagem, da representação); uma força produzindo escrituras que eludem o nada (que significam) e (o) transformam (em) tudo.

\section{REFERÊNCIAS BIBLIOGRÁFICAS}

Baudrillard, J. (1976). Kool Killer ou a insurreição pelos signos. In Cine-olho. Revista de cinema, 5/6. Jun. Jul. Ago. 1979.

Castleman, C. (1982). Getting up - subway graffiti in New York. Cambridge, Massachussetts: The MIT Press.

Castro, L. R. (2001). Da invisibilidade à ação: crianças e jovens na construção da cultura. In Castro, L. R. (org.) Crianças e jovens na construção da cultura. Rio de Janeiro, RJ: NAU Editora: FAPERJ, 2001.

Fernandes, F. L. (2005). Psicanálise e laço social. Documento interno de trabalho do Tempo Freudiano Associação Psicanalítica. Rio de Janeiro, RJ (mimeografado).

Freitas, M. T. de A. (2001). A escrita de adolescentes na Internet. In Psicologia Clínica. Rio de Janeiro, RJ: Pontifícia Universidade Católica do Rio de Janeiro. vol. 12 no. 2, 2001.
Freud, S. (1925). A negativa. In Edição Standard Brasileira das Obras Psicológicas Completas .J. Salomão, trad.) (v. 19, pp. 295 300) Rio de Janeiro, RJ: Imago, 1976.

Glynos, J. (2002). Psychoanalysis operates upon the subject of science: Lacan between science and ethics. In Glynos, J. and Stavrakakis, Y. (orgs) Lacan \& Science. Londres: H. Karnac Books.

Hottois, G. (1992). Le règne de l'opératoire. In Prades, J. (org.) La technoscience. Paris: L'Harmattan.

Jean, G. (2002). A escrita: memória dos homens. (L. M. Amaral, trad.) Rio de Janeiro, RJ: Objetiva.

Koyré, A. (1961). Études Newtoniennes. Paris: Gallimard, 1991.

(1966). Études D'Histoire de la Pensée Scientifique. Paris: Gallimard, 1985.

Lacan, J. (1957-8). Le séminaire livre V: Les formations de l'inconscient. Paris: Seuil, 1998.

(1965). La science et la vérité. In Écrits. Paris: Seuil,1966.

(1968). Proposition du 9 octobre 1967 sur le psychanalyste de l'École. In Autres Écrits Paris: Seuil, 2001.

(1969-70). O Seminário, Livro XVII: O Avesso da Psicanálise, (Roitman, A., trad.) Rio de Janeiro, RJ: Jorge Zahar, 1992.

(1972-73). O Seminário, Livro XX: Mais, ainda. (Magno, M. D., trad.) Rio de Janeiro, RJ: Jorge Zahar, 1996.

(1978). L'étourdit. In Autres écrits. Paris: Seuil, 2001.

Lebrun, J-P. (1997) Un monde sans limite. Ramonville Saint-Agne: Erès

Melman, Ch. (1997). Os adolescentes estão sempre confrontados ao minotauro. In Adolescência entre o passado e o futuro. Porto Alegre, RS: Artes e Ofícios, 1997.

(2001). Qu'attend l'adolescent de la sexualité et de la mort? In Journal Français de Psychiatrie no. 14; 2001.

(2002). L'homme sans gravite: jouir 
à tout prix - Entretiens avec Jean-Pierre Lebrun. Paris: Denoël, 2002.

Sampaio, L. S.(2000). A matematicidade da matemática surpreendida em sua própria casa, nua, na passagem dos semigrupos aos monóides. In Sampaio, L.S. Lógica Ressuscitada: Sete Ensaios. Rio de Janeiro, RJ: UERJ.

Saussure, F. (1916). Curso de lingüistica geral (Org. Bally, C. e Sechehaye, A.). São Paulo, SP: Cultrix; 9a. edição S. D.

\section{NOTAS}

${ }^{1} \mathrm{O}$ artigo faz parte da pesquisa em andamento sobre adolescência como indicador dos efeitos da ciência sobre o campo do sujeito no Programa de Pós-Graduação em Teoria Psicanalítica do IP/UFRJ, com apoio da FAPERJ.

2 Não cabe retomar aqui as questões envolvidas na definição de um conceito psicanalítico de adolescência. Para o que concerne a este trabalho, falar de adolescência é falar de uma etapa lógica da articulação do sujeito na estrutura, definida pelo encontro com o real do desejo sexuado como aquilo que excedendo (Lacan diz ex-sistindo) à estrutura lógico-simbólica, recai ao encargo do sujeito desejar, assumir em nome próprio (às custas de sua própria condição de sujeito desejante). O que aqui se propõe é pensar a adolescência, como momento inaugural dessa emergência do sujeito enquanto pura diferença, destituído de qualquer marca originária que intrinsecamente o identificaria a si e para si mesmo.

3 Os significantes do Nome-do-Pai e o Phallus, tais como definidos formalmente por Lacan (1957-58), são exemplos desse tipo de operadores.
${ }^{4}$ Em 1987, o então secretário de polícia do Rio de Janeiro, Dr. Nilo Batista, recorria aos jornais para fazer um apelo e colocar-se à disposição: "Se eles (referindo-se aos pichadores que andavam dando trabalho) têm algo a dizer, podemos conversar, dialogar" $(\mathrm{O}$ Globo 25/1/87).
Recebido em abril/ 2005. Aceito em maio/ 2005. 